\title{
eLabEL: Living Labs for Implementation and Evaluation of Integrated Technology in Primary Care
}

\author{
Lex van Velsen \\ Biomedical Signals and Systems \\ group, University of Twente \& \\ Telemedicine cluster, Roessingh \\ Research and Development \\ P.O. Box 217, $7500 \mathrm{AE}$ \\ Enschede, the Netherlands \\ I.vanvelsen@rrd.nl
}

\author{
Wendy Oude Nijeweme \\ d'Hollosy \\ Biomedical Signals and Systems \\ group \\ University of Twente \\ P.O. Box 217, $7500 \mathrm{AE}$ \\ Enschede, the Netherlands \\ w.dhollosy@utwente.nl
}

\author{
Hermie Hermens \\ Biomedical Signals and Systems \\ group, University of Twente \& \\ Telemedicine cluster, Roessingh \\ Research and Development \\ P.O. Box 217, $7500 \mathrm{AE}$ \\ Enschede, the Netherlands \\ h.hermens@rrd.nl
}

\begin{abstract}
In order to implement integrated eHealth technology in primary care, and to study implementation plans, and uptake and effect of these applications, we will establish ten living labs in the Netherlands. Together, these living labs make up the 'eLabEL project'. For these ten living labs, we will determine where eHealth technology can provide added value, and, together with companies, we will implement relevant applications. Next, patients' and caregivers' view on care with and without technology will be investigated, as well as the use and usefulness of technology for specific target populations in primary care (e.g., COPD patients). A special focus will also be placed on developing decision support tools for caregivers. Finally, we will study optimal implementation strategies throughout the project. After three years a durable living lab infrastructure should be established in which companies and research organizations can develop and test eHealth innovations for primary care. This paper aims to spark the discussion on how to set up these kinds of Living Labs.
\end{abstract}

\section{Categories and Subject Descriptors}

J.3 [Life and Medical Sciences]: Health, Medical information systems.

\section{General Terms}

Algorithms, Management, Measurement, Design, Human factors, Standardization.

\section{Keywords}

eHealth, primary care, living labs, interoperability, design, decision support

\section{INTRODUCTION}

Although their effectiveness has been assessed time and time

Permission to make digital or hard copies of all or part of this work for personal or classroom use is granted without fee provided that copies are not made or distributed for profit or commercial advantage and that copies bear this notice and the full citation on the first page. To copy otherwise, to republish, to post on servers or to redistribute to lists, requires prior specific permission and/or a fee.

PervasiveHealth 2014, May 20-23, Oldenburg, Germany

Copyright $\odot 2014$ ICST 978-1-63190-011-2

DOI 10.4108/icst.pervasivehealth.2014.254933 again, telemedicine services are not widely used in practice [1]. A number of studies have identified several causes for this, such as a lack of end-user involvement in design, a lack of familiarity with the technology, a lack of organizational embedding, etcetera [2]. In order to overcome a set of the most problematic issues, we will start 10 living labs in large primary care centers: the eLabEL project. In this project, we will integrate different Telemedicine applications and platforms, study implementation strategies, and determine the added value of (integrated) telemedicine technology within primary care on a large scale basis. These living labs must serve as a showcase for displaying the role technology can play in primary care, thereby contributing to the innovation climate in this sector.

In this paper, we will discuss what we understand a living lab to be, how they will be set up, and how they will serve to gain a better understanding of supporting primary health care with telemedicine technology. This way, we aim to spark the discussion on how to set up these kinds of Living Labs.

\section{WHAT IS A LIVING LAB?}

There are many different notions on what a living lab entails. Our vision is in line with the definition of a living lab, given by the European Network of Living Labs [3]:

"A Living Lab is about experimentation and co-creation with real users in real life environments, where users together with researchers, firms and public institutions look together for new solutions, new products, new services or new business models."

Translated to a primary health care setting, a living lab is a primary health care center where new technological solutions are developed, introduced and evaluated in cooperation with health professionals, patients and companies. Besides, a living lab also serves scientific research by supporting a research infrastructure.

\section{DECISION SUPPORT}

When a lot of data is collected about a patient (often referred to as Big Data), caregivers may be provided with automated recommendations for helping a patient. The source for such recommendations can be the data of a whole patient population from which insights have been extracted. These decision support tools have been found to improve clinical practice, but should be made as easy to use as possible and in line with the caregiver's work [4]. In the eLabEL project, we will integrate existing or develop new design decision support tools for primary care, so as to increase the quality of care. Hereby, we will take a human- 
centered approach, and first identify the contexts in which General Practitioners, nurse practitioners and physical therapists can benefit from decision support. Next, we will match these opportunities with existing technologies, or develop (machinelearning based) decision support algorithms that utilize the big data in the eLabEL living labs. Finally, visualization methods for displaying decision support will be created and tested. As this method is user-led, it is therefore unsure what exactly decision support will look like after three years.

\section{PROJECT SETUP 4.1 Project Partners}

The eLabEL project team consists of people working at four Dutch universities and knowledge organizations. The main task of Nivel is to set up the living lab environments within ten primary care centers. The University of Twente's main concern is to guide the integration of the telemedicine technologies and to explore the possibilities for decision support systems. Maastricht University is focused on evaluations on both a clinical and subjective level. TNO, finally, will study the organizational implementation of the integrated telemedicine applications. About ten commercial partners will be involved that supply technology. These companies range from producers of web based eHealth coaches to sensor developers to datacenter builders. Finally, ten primary health care centers will participate in the eLabEL project as a living lab. These centers must have at least one general practitioner, a nurse practitioner, and a physical therapist.

\subsection{Time Plan}

The goal of the eLabEL project is to create durable living lab environments for primary care. In other words, after a few years, there should be an environment in which new eHealth technology can be developed and evaluated within a real-life care setting. For now, the first three years of the projects have been planned.

In the first year (which started on September 1, 2013), the project team will recruit the 10 living labs. For each of these living labs, we will explore the care professionals' and patients' wishes and needs regarding eHealth solutions, and we will inventory the health care centers' technological infrastructure. More specifically, professionals and patients will be consulted during several iterations (e.g., via interviews, creative workshops). This way, they have a large say in the technology design. Next, we will set up a patient panel for each center (with about 250 members) via which we will question patients about their view on how the introduction of new technology has affected the care provided by the center (with a baseline measure before introducing any technology). At the same time, the companies and the project team will work towards an integrated package of eHealth technology that can be offered to the primary care centers and that can communicate with electronic patient records. Such a package will go accompanied by an implementation plan and business model, which will be developed in collaboration with companies and health organizations.

All living labs will receive an annual upgrade of their package of eHealth technology. What this upgrade entails will depend on the wishes of the care organizations and the technologies the different companies create during this time. In these years, specific technologies for specific target groups (e.g., applications for COPD patients) will be evaluated with the target population by means of a longitudinal study design. Finally, primary health care centers that participate as living lab and 'normal' primary health care centers will be compared in terms of patients' complaints presentations and medical consumption.

Throughout the project, attention will be given to the issues that have hindered or accelerated implementation of the different technologies. These will be gathered via focus groups and interviews with care professionals and their managers.

\section{CONCLUDING REMARKS}

eLabEL is an ambitious project that has the potential to be the origin of novel telemedicine technologies, to increase the level of technology use within 10 primary care centers (and as a result, might inspire other centers as well), and to increase our understanding of why certain telemedicine technologies do or do not work. Most importantly, however, eLabEL might be the project that finally provides an integration solution for all the different, stand-alone telemedicine applications that are currently available on the market. Once the foundation has been laid, we hope that the eLabEL project will expand with even more companies and telemedicine innovations.

\section{ACKNOWLEDGMENTS}

This work has been conducted within the context of the eLabEL project. eLabEL aims to contribute to the sustainability of primary care by developing, implementing and evaluating innovative, integrated Telemedicine technology by means of a Living Lab approach. More information can be found at: http://www.caretechnologyresearch.nl/elabel

eLabEL is a project of the Center for Care Technology Research (http://www.caretechnologyresearch.nl)

This work is partly funded by a grant from the Netherlands Organization for Health Research and Development (ZonMw); grant number: 10-10400-98-009

\section{REFERENCES}

[1] Zanaboni, P. and Wootton, R. Adoption of telemedicine: from pilot stage to routine delivery. BMC medical informatics \& decision making, $12,1$.

[2] Broens, T. H. F., Huis in 't Veld, R. M. H. A., VollenbroekHutten, M. M. R., Hermens, H., Van Halteren, A. T. and Nieuwenhuis, L. J. M. Determinants of successful telemedicine implementations: a literature study. Journal of telemedicine and telecare, 13, 6, 303-309.

[3] European Network of Living Labs Open Living Labs. Accessed on December 13, 2013, at: http://www.openlivinglabs.eu/

[4] Kawamoto, K., Houlihan, C. A., Balas, E. A. and Lobach, D. F. Improving clinical practice using clinical decision support systems: a systematic review of trials to identify features critical to success. British Medical Journal, 330, 7494, 765. 